\title{
Optimization of spray parameters for effective microchannel cooling using surface response methodology
}

\author{
Sasmita Ball $^{1 *}$, Purna C. Mishra ${ }^{1}$, Ashok K. Satapathy ${ }^{2}$ \\ ${ }^{1}$ KIIT Deemed to be university, Bhubaneswar, Odisha 751024, India \\ ${ }^{2}$ NIT, Rourkela, Odisha 769008, India
}

Corresponding Author Email: sasmitabal@gmail.com

https://doi.org/10.18280/ijht.360325

Received: 7 February 2018

Accepted: 7 September 2018

\section{Keywords:}

heat transfer, microchannel cooling, optimization, response surface method, spray impingement

\begin{abstract}
Spray technology has numerous applications in general and cooling microchannels in particular. But before that study of the controlling parameters on which spray performance depends need to be explored. Present work describes an experimental study on microchannel cooling with jet and spray at different pressure combinations of air and water. The experimental facility was developed at the School of Mechanical Engineering, KIIT, deemed to be University, Bhubaneswar, to investigate the effect of various controlling parameters like fluid pressure, flow rate, nozzle to surface distance and heat input on jet and spray cooling of microchannels. The input parameters like air pressure and water pressure along with nozzle to surface distance were optimized. The input parametrs such as air and water pressure in the range of 1 bar to 3 bar, nozzle tip to surface distance in the range of 10 to $20 \mathrm{~mm}$ were considered during the tests. As a result, at 1 bar air pressure, 3 bar water pressure and 17.42 $\mathrm{mm}$ nozzle tip to surface distance, the maximum heat transfer coefficient was achieved as predicted optimal solution through response surface methodology (RSM). The data were compared with that of the earlier researcher's experimental work. The experimental results revealed that the employment of spray impingement cooling technique on microchannels provided significant improvement in removal of heat flux with less consumption of coolant.
\end{abstract}

\section{INTRODUCTION}

Within past few years electronic industry developed vastly. Emerging technologies tends to increase demand for higher power densities in small dimensions [1-2]. Hence, performance of the equipment used for military or electronic industry needs high heat removal from small areas which directly increase its performance. Natural convection or forced convection of air and water is proved to be inadequate for this purpose. So, hybrid cooling which takes advantage of both microchannel and spray impingement considered as two best technologies for high heat flux removal is taken into consideration. Though spray cooling has got significant application in agriculture, medical, laser, aviation, steel quenching and casting cooling etc., it can be more extended for microelectronics cooling. Study of the controlling parameters on which spray performance depends is yet to be explored.

Sprays have proved their effectiveness in removing high heat flux due to low mass flow rate and small surface overheating, which are mandatory requirements in the thermal design of microelectronics [3-4]. Spray cooling has the advantage of uniform wall temperature and reduced coolant flow rate compared to jet impingement cooling [5-6] This is possible because of the broad dispersion of incoming liquid into number of small droplets which increases surface area to volume ratio of the liquid before impingement on the surface and the part of heated area coming directly in contact with the liquid [7-9]. Past investigations reveal that most of the work related to spray is on boiling regime so as to remove high heat flux, however, spray cooling has been identified as a potential means of dissipating high heat fluxes at surface temperatures below the liquid saturation temperature like in computer electronics [10]. The non-boiling regime's spray also plays a vital part of spray cooling process as the flow instabilities associated with boiling regime is not present [11]. Here the temperature of the heated surface is below the boiling temperature of the coolant. During spray, all the droplets of liquid accumulate and form a liquid film on the heated surface which gets swiped by the next upcoming fresh liquid droplets. The flow of the liquid becomes turbulent gradually and appreciable amount of heat flux is removed due to latent heat of evaporation and forced convection [12]. Oliphant et al. [13] demonstrated heat transfer phenomena in non-boiling regime using air-assisted nozzle. They concluded that liquid mass flux along with droplet velocity is the key parameters that influence heat transfer rate. In order to realize heat transfer enhancement and characteristics through spray cooling, researchers have made numerous efforts to conduct parametric studies on spray phenomena [14]. Spray cooling has been successfully implemented in thermal management of microelectronics [1518]. Single jet and multi jet cooling were proposed by many researchers [19-21]. Parametric investigation was done by very few researchers where they reported that pressure of the coolant, nozzle to surface height and mass flux impingement has a vital role to play [22-26]. Effect of injection angle on heat transfer characteristics with multiple inclined array of jets is also studied and found heat transfer enhancement of about $9 \%$ compared to normally used configuration [27]. Study of different additives to coolant during spray reveals that it 
enhances heat transfer up to a limit after which it decreases [28]. Spray cooling application in different field for fast cooling was studied by many searchers [29-33]. Experimental and numerical investigation of heat transfer characteristics of urea-water solution spray impingement on stainless steel plate was done and the effect of flow regimes on heat transfer found to be more predominant [34]. Considerable experimental and analytical work has been reported till now, but very few literature are available related to optimization of the parameters that affect performance of jet and spray, putting attention on that will enhance the purpose of more heat transfer from the heated surface [35-38].

Present work describes an experimental study of air and water jet along with spray at different pressure combinations of air and water on microchannel cooling. The microchannel was designed and fabricated using Die Sinking Electro Discharge Machining with selected parameters to get proper surface finish. The copper test section of dimension $27 \mathrm{~mm} x$ $25 \mathrm{~mm}$ with $4 \mathrm{~mm}$ thickness and having 11 numbers of channels of high aspect ratios fabricated on its surface was used for the experiment. An experimental facility was developed at the School of Mechanical Engineering, KIIT University, Bhubaneswar, to investigate the effect of various controlling parameters like Fluid Pressure, Flow Rate, Nozzle to surface distance and Heat Input on spray cooling of microchannels. The input parameters like air pressure and water pressure along with nozzle to surface distance were optimized. The optimized result was used in the current experiment. Average mass impingement was calculated using mechanical patternator designed and developed in the laboratory. Heat was given from the base using two cartridge heaters of 75 watt, 230 volt inserted in a groove which was drilled in a copper block. The microchannel heat sink and the copper block surface was pasted using thermal adhesive so as to ensure no air gap and heat conduction in one dimension. $\mathrm{K}$ type thermocouples were inserted in the heater block as well as different locations of microchannel to get the temperature data and the data were acquired by Data Acquisition System and analysis was done using Zaila Software. Due to experimental safety reason heat input was limited to 20-80
Watt. The data was compared with the previous experimental work and it was found that spray impingement on microchannels with the present input parameters shows better result in terms of high heat transfer coefficient and cooling rate with less expenditure of coolant.

\section{EXPERIMENTAL SETUP AND PROCEDURE}

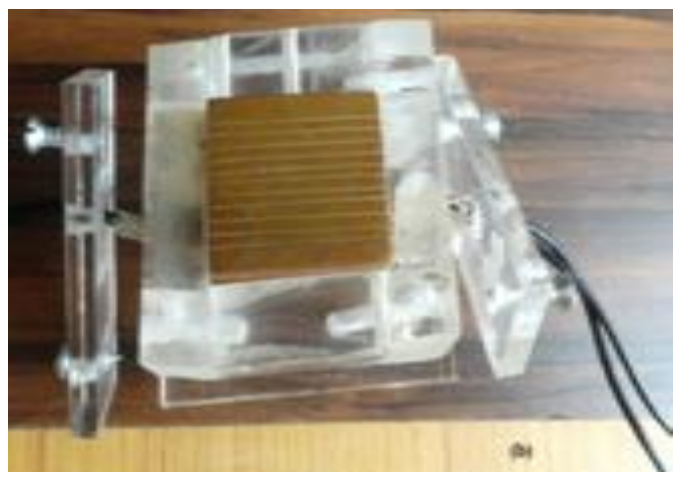

Figure 1. Heater attachment method

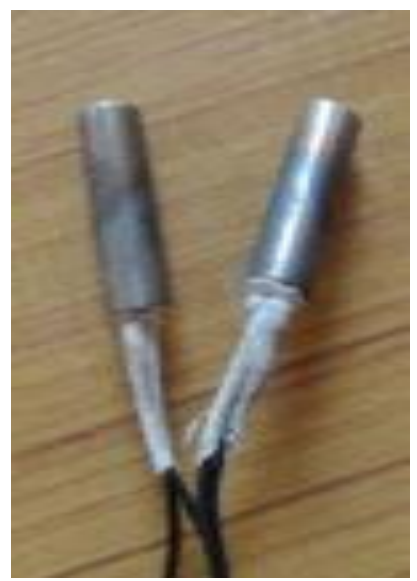

Figure 2. Super watt cartridge heaters

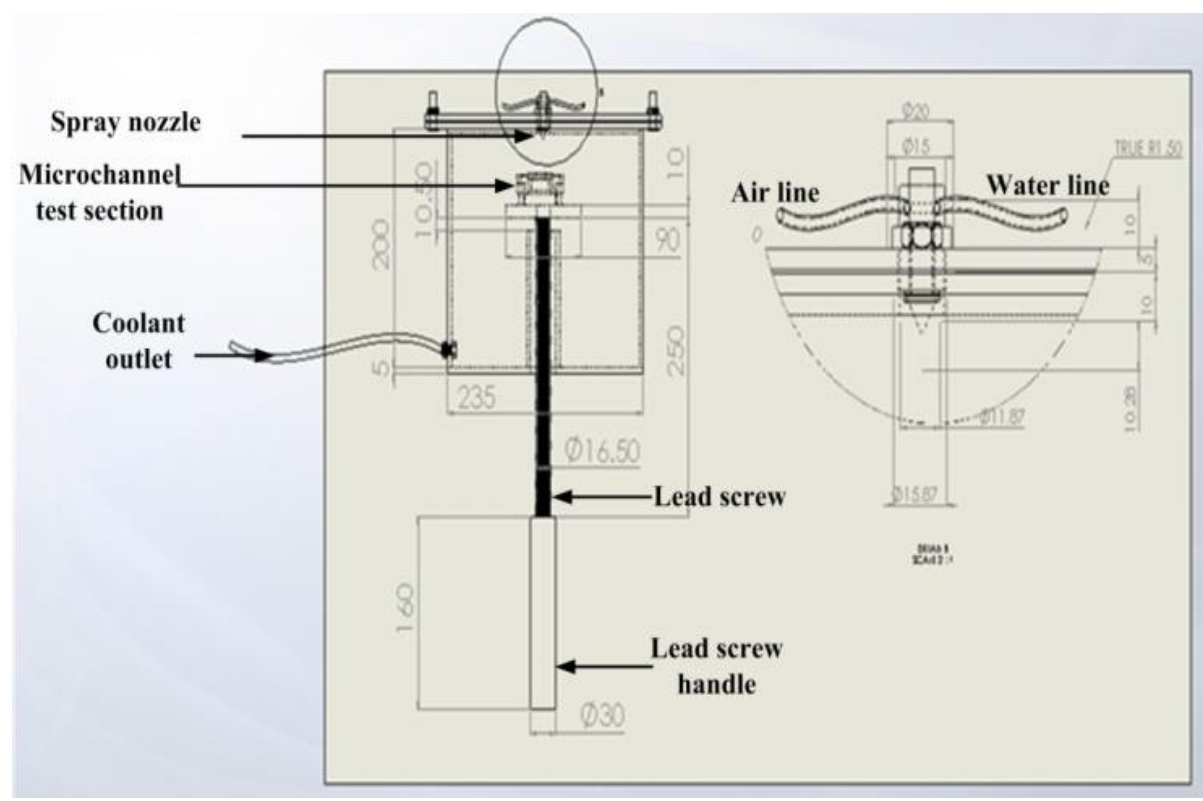

(a) Spray arrangement 


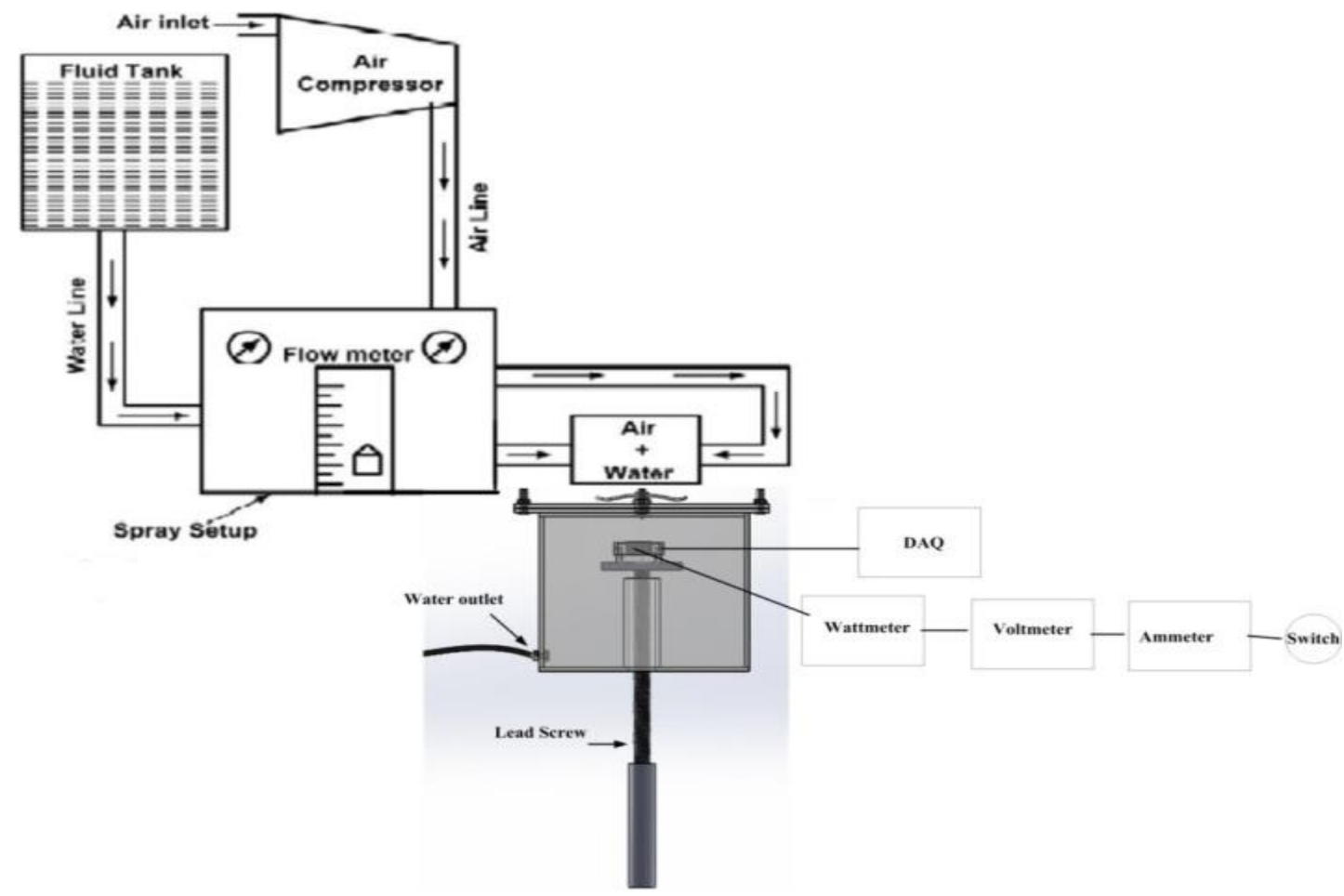

(b) Circuit diagram of experimental set-up

Figure 3. Schematic of complete set-up for spray cooling

The investigation was performed with the help of an experimental set up designed and self-fabricated in the laboratory with the facility of spray equipment, heating arrangement and data acquisition system for recording of the temperature data. The recorded data is further analyzed by Zyla Software. An air compressor was used to provide compressed air to the spray set-up for atomization of the fluid particle. The test specimen used in the present investigation is a copper plate of dimension $(27 \mathrm{~mm} \times 25 \mathrm{~mm} \times 4 \mathrm{~mm})$ on the top of which 11 number of grooves of hydraulic dia. $150 \mu \mathrm{m}$ were inscribed as shown in Figure 1. Below the microchannel plate, an oxygen free copper block with two 200 watt, 230volt AC cartridge heaters as shown in Figure 2 embedded within is used to heat the microchannel. Thermocouple establishment is essential in the temperature estimation, and it decides the precision of measured temperature information. As the tip of the thermocouple is very small and it could just quantify the temperature of a point touched with it, so it is important that the contact point between thermocouple tip and measured point must be touched well. In this study, thermocouples were implanted $0.25 \mathrm{~mm}$ below the surface. $0.1 \mathrm{~mm}$ diameter wires (Chromel and Alumel) that are insulated from each other by $\mathrm{MgO}$ powder and sheathed with stainless steel 304 is used as thermocouple. The outer diameter of sheath is $0.4 \mathrm{~mm}$. Four numbers of wires from each of Chromel and Alumel was taken and tip was made by soldering. The tip made was of diameter less than $1 \mathrm{~mm}$ so that it can be easily inserted into the micro drilled hole on heat sink and heater block. The portion of thermocouple which stays inside the acrylic was covered by Teflon tape and rest part was inside the sheath.

To reduce the heat loss, thermal adhesive was used between heater block upper surface and microchannel plate base. To ensure no heat loss to outside, acrylic cover was used within which both heater block and microchannel plate were inserted The complete set-up is shown in detail in Figure 3.

\section{DESIGN OF EXPERIMENTS}

Table 1. CCF RSM based coded experimental design matrix

\begin{tabular}{ccc}
\hline A: $\mathrm{p}_{\mathrm{w}}$ in bar & B: $\mathrm{pa}$ in bar & $\mathrm{C}:(\mathrm{H})$ in $\mathrm{mm}$ \\
\hline 1 & 1 & 10 \\
3 & 1 & 10 \\
1 & 3 & 10 \\
3 & 3 & 10 \\
1 & 1 & 20 \\
3 & 1 & 20 \\
1 & 3 & 20 \\
3 & 3 & 20 \\
1 & 2 & 15 \\
3 & 2 & 15 \\
2 & 1 & 15 \\
2 & 3 & 15 \\
2 & 2 & 10 \\
2 & 2 & 20 \\
2 & 2 & 15 \\
2 & 2 & 15 \\
2 & 2 & 15 \\
2 & 2 & 15 \\
2 & 2 & 15 \\
2 & 2 & 15 \\
\hline
\end{tabular}

Box-Wilson Central Composite Design, also known as 'central composite design', contains fractional factorial design with central points that is augmented with a group of 'star points' that allows prediction of curvature. Among the three varieties of central composite design, Face centered (CCF) design is used in the current research. In this design, the star points are at the center of each face of the factorial. As we are having 3 levels of each factor, $\mathrm{CCF}$ is suitable for the current problem. By using this, non-sequential experiments having fewer design points are used to get the experimental design matrix. Water pressure $\left(\mathrm{p}_{\mathrm{w}}\right)$, air pressure $\left(\mathrm{p}_{\mathrm{a}}\right)$ and nozzle-to- 
surface height $(\mathrm{H})$ are the three input parameters. Three levels of the input parameters are used. Twenty experimental runs were obtained by this method to conduct the experiments. Table 1 shows the input parameters with their levels and the design matrix along with the experimental results.

\section{EXPERIMENTAL PROCEDURE}

Nozzle to microchannel surface distance was fixed to 10 $\mathrm{mm}, 15 \mathrm{~mm}$ and $20 \mathrm{~mm}$ to mark the difference of nozzle to target distance on cooling rate. After setting the wattmeter to 40Watt, thermocouple readings were observed till a steady state temperature was achieved. When the temperature was reached about $95^{\circ} \mathrm{C}$, it was set-up for the experimentation. Air pressure, water pressure and the air flow rate were preset to the required values. Once the desired temperature was achieved, the heater was turned off and simultaneously spray was on till a steady state room temperature was achieved. The experiment was then repeated for different operating pressures of both water and air combinations. The range pressure range for both water and air was varied from (0-2) bar. The water flow rate was noted from the rotameter installed in the spray set-up. A Data Acquisition System (DAQ) served as the tool to register the transient temperature data. The outcomes of the spray cooling were generated systematically at different conditions and with different parameters. The recorded temperature data were analyzed using Zaila software environment. Every time before starting the experiment, water temperature was recorded using IR camera.

The rate of heat transfer from the surface depends on the coolant temperature and the convective heat transfer coefficient. Hence, to determine the effective cooling performance of the set-up convective heat transfer coefficient is necessary. The convective heat transfer coefficient $(h)$ is the proportionality coefficient between the heat flux (q) and the temperature difference between the surface and the coolant $\left(\mathrm{T}_{\mathrm{s}}-\mathrm{T}_{\mathrm{c}}\right)$. The surface HTC $(h)$ can be calculated from Equation 1 as used by Nayak et al. [39].

$h=\frac{q}{\left(T_{s}-T_{c}\right)}$

where $\mathrm{q}=$ Heat flux

$T_{s}=$ Surface temperature

$T_{c}=$ Coolant temperature

\section{EXPERIMENTAL OUTCOMES}

In the present study, the response is the heat transfer coefficient which can be computed by using the Equation 1 at various operating conditions. The magnitude of the result at different set of controlling parameters is represented in Table 2 .

Table 2. Experimental outcomes

\begin{tabular}{ccccc}
\hline & Factor 1 & Factor 2 & Factor 3 & Response \\
\hline Run & A:Water Press. $\left(\mathrm{p}_{\mathrm{w}}\right)$ & B:Air Press. $\left(\mathrm{p}_{\mathrm{a}}\right)$ & C:Nozzle Height $(\mathrm{H})$ & Heat Transfer Coeff. $(h)$ \\
& bar & bar & Wm & W/m... \\
1 & 1 & 1 & 10 & 1521.48 \\
2 & 3 & 1 & 10 & 1789.12 \\
3 & 1 & 3 & 10 & 1210.93 \\
4 & 3 & 3 & 10 & 1467 \\
5 & 1 & 1 & 20 & 1678.48 \\
6 & 3 & 1 & 20 & 2374 \\
7 & 1 & 3 & 20 & 1423.78 \\
8 & 3 & 3 & 20 & 1526.7 \\
9 & 1 & 2 & 15 & 1623.54 \\
10 & 3 & 2 & 15 & 2115 \\
11 & 2 & 1 & 15 & 2099 \\
12 & 2 & 3 & 15 & 1581.85 \\
13 & 2 & 2 & 10 & 1463.23 \\
14 & 2 & 2 & 20 & 1598.23 \\
15 & 2 & 2 & 15 & 1692.23 \\
16 & 2 & 2 & 15 & 1686 \\
17 & 2 & 2 & 15 & 1693 \\
18 & 2 & 2 & 15 & 1692.2 \\
19 & 2 & 2 & 15 & 1694.2 \\
20 & 2 & 2 & 15 & 1687.48 \\
\hline
\end{tabular}

\section{RESULTS AND DISCUSSION}

\subsection{Empirical model development using response surface methodology}

From the regression analysis and the quadratic model developed, the expression for heat transfer coefficient is given in Equation 2.

$\mathrm{HTC}=-317.112+91.757 \times \mathrm{p}_{\mathrm{w}}-300.38 \times \mathrm{p}_{\mathrm{a}}+283.68 \mathrm{H}-$
$75.52 \times \mathrm{p}_{\mathrm{a}} \times \mathrm{p}_{\mathrm{w}}+6.86 \times \mathrm{p}_{\mathrm{a}} \times \mathrm{H}-11.73 \times \mathrm{p}_{\mathrm{a}} \times \mathrm{H}-29.40 \times \mathrm{p}_{\mathrm{w}}{ }^{2}$ $+100.56 \times \mathrm{pa}^{2}-8.36 \times \mathrm{H}^{2}$.

\subsection{Response surface analysis}

The response surface analysis of the experimental results was performed by Design Expert 8 software. Figure 4 shows the change of HTC in regard to air and water pressure. It is observed that water pressure has a significant effect on heat transfer coefficient in comparison to air pressure. The 
maximum value of heat transfer coefficient was obtained at a higher level of water pressure and lower level of air pressure. Since the atomization of the water particle becomes more pronounced at higher air pressure, which enables maximum blown-up of the water droplets and thus, less amount of coolant touches the heated surface, which in turn decreases the heat transfer coefficient. Figure 5 shows the variation of heat transfer coefficient with respect to water pressure and nozzle height. As water pressure increases heat transfer coefficient increases. This might be due to the reason that with increase in water pressure more water particle was able to penetrate upto the target surface. Though there was a contribution of air in overall cooling performance, more is the air pressure compared to the water pressure, many of the water particles were blown off the target surface, hence the cooling was not effective. Of course, this result also depends on the nozzle tip to target surface distance. While varying the nozzle tip to target surface distance, it was realized that when the nozzle height increases heat transfer coefficient increases for a certain height and after that it decreases. Figure 6 shows change of HTC in regard to air pressure and nozzle height. It shows significant effect of air pressure and nozzle height on heat transfer coefficient.

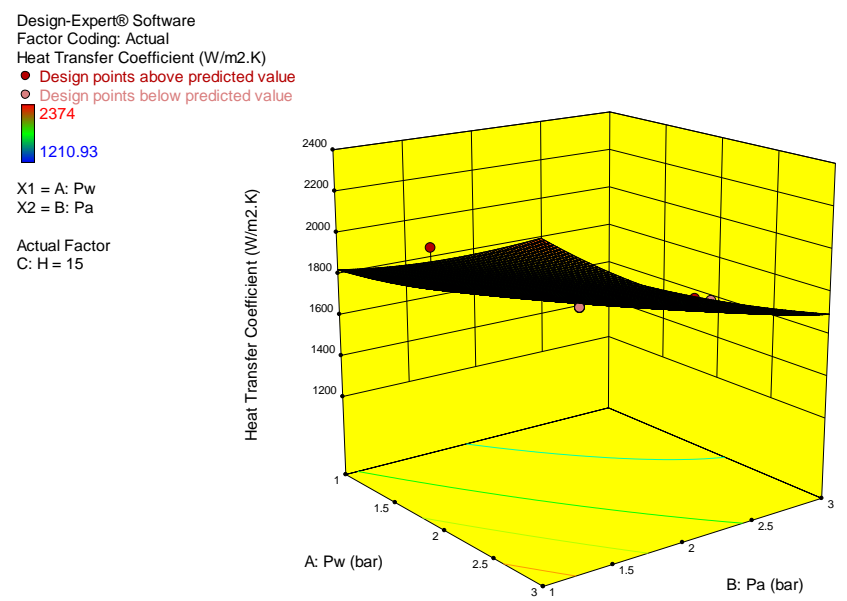

Figure 4. Variation of heat transfer coefficient with respect to air and water pressure at nozzle height $15 \mathrm{~mm}$

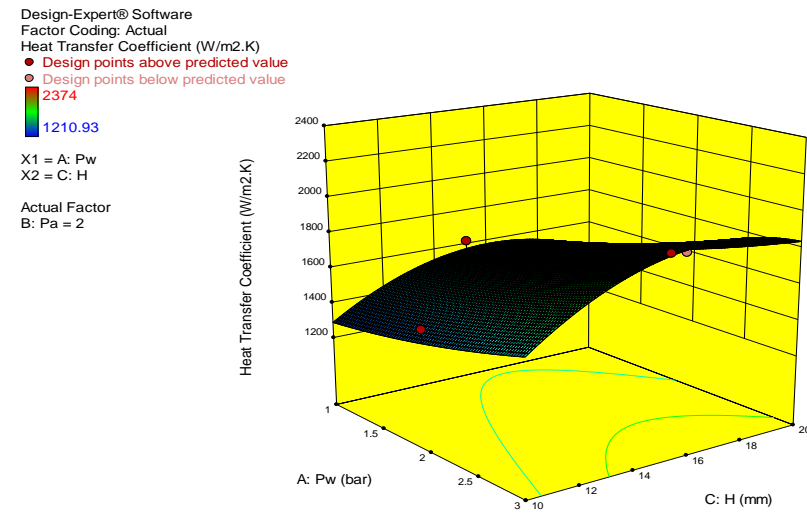

Figure 5. Variation of heat transfer coefficient with respect to air pressure and nozzle height at air pressure 2 bar

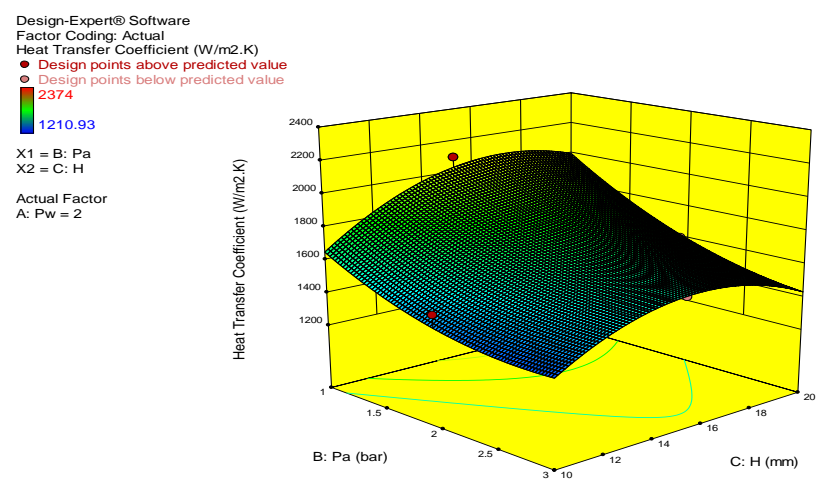

Figure 6. Variation of heat transfer coefficient with respect to air pressure and nozzle height at water pressure 2 bar

\subsection{Adequacy test for model}

The $P$ value is less than 0.05 , which signifies that the model is in $99 \%$ confidence level. It can also be seen that the normal plot of residuals lies well near predicted values. Values of probability below 0.05 indicate model terms A, B, C, AC and $\mathrm{C}^{2}$ are significant. Values greater than 0.1 indicate the model terms are not significant. Table 3 shows adequacy test for the model.

Table 3. Adequacy test for the model

\begin{tabular}{|c|c|c|c|c|c|}
\hline Source & Sum of Squares & DOF & Mean Square & F value & P-value \\
\hline Model & $1.110 \mathrm{E}+006$ & 9 & $1.234 \mathrm{E}+005$ & 20.84 & $<0.0001$ \\
\hline$A-p_{w}$ & 2.604E+005 & 1 & 2.604E+005 & 43.98 & $<0.0001$ \\
\hline B-pa & $5.071 \mathrm{E}+005$ & 1 & $5.071 \mathrm{E}+005$ & 85.64 & $<0.0001$ \\
\hline C-H & $1.321 \mathrm{E}+005$ & 1 & $1.321 \mathrm{E}+005$ & 22.31 & 0.0008 \\
\hline $\mathrm{AB}$ & 45627.67 & 1 & 45627.67 & 7.71 & 0.0196 \\
\hline $\mathrm{AC}$ & 9434.57 & 1 & 9434.57 & 1.59 & 0.2355 \\
\hline $\mathrm{BC}$ & 27533.83 & 1 & 27533.83 & 4.65 & 0.0564 \\
\hline$A^{2}$ & 2377.87 & 1 & 2377.87 & 0.40 & 0.5405 \\
\hline $\mathrm{B}^{2}$ & 27809.11 & 1 & 27809.11 & 4.70 & 0.0554 \\
\hline $\mathrm{C}^{2}$ & $1.203 \mathrm{E}+005$ & 1 & $1.203 \mathrm{E}+005$ & 20.31 & 0.0011 \\
\hline Residual & 59207.05 & 10 & 5920.70 & & \\
\hline Lack of Fit & 59152.60 & 5 & 11830.52 & 1086.34 & $<0.0624$ \\
\hline Pure Error & 54.45 & 5 & 10.89 & Cor Total & $1.170 \mathrm{E}+006$ \\
\hline $\mathrm{R}^{2}$ & 0.95 & & Adj $R^{2}$ & 0.90 & \\
\hline
\end{tabular}

\subsection{Response surface optimization}

The response surface optimization was done to find the optimal condition in which the maximum heat transfer coefficient was achieved. The condition is mentioned in Table 4. Figure 7 shows the normal plot of residuals which indicates that data are normally distributed. 
Table 4. Optimized response prediction

\begin{tabular}{cccccc}
\hline Sl. No. & $\mathbf{p}_{\mathbf{w}}(\mathbf{b a r})$ & $\mathbf{p}_{\mathbf{a}}(\mathbf{b a r})$ & Nozzle height $(\mathbf{m m})$ & $\boldsymbol{h}\left(\mathbf{W} / \mathbf{m}^{2} \cdot \mathbf{K}\right)$ & Desirability \\
\hline $\mathbf{1}$ & 3 & 1 & 17.425 & 2408.341 & 0.99 \\
\hline
\end{tabular}

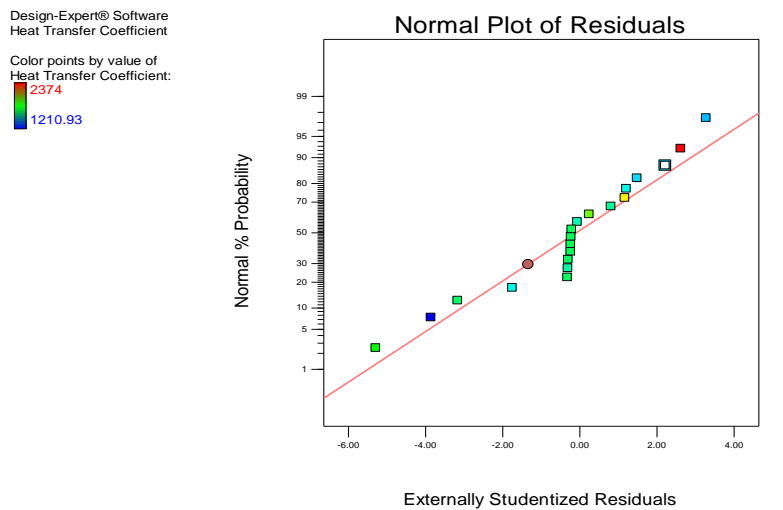

Figure 7. Normal plot of Residuals

\subsection{Experimental validation}

Test was carried out at the predicted optimal parametric conditions, i.e. for $\mathrm{p}_{\mathrm{w}}=3 \mathrm{bar}, \mathrm{p}_{\mathrm{a}}=1$ bar and Nozzle height $=$ $17.425 \mathrm{~mm}$. The same procedure was followed to calculate heat transfer coefficient in these conditions. In the repeat experiment at the optimal conditions, $h$ value was found to be $2394.31 \mathrm{~W} / \mathrm{m}^{2}-\mathrm{K}$. Comparing this data of $h$ with the primary data, it confirmed the experimental validity with a small deviation. This may be due to the fact that the data taken were nearly equal to the optimal values, i.e. $\mathrm{p}_{\mathrm{w}}=3$ (bar) and $\mathrm{p}_{\mathrm{a}}=1$ (bar), Nozzle height $=18 \mathrm{~mm}$.

\subsection{Effect of power input on heat transfer coefficient}

Table 5. Comparison of current data with data available

\begin{tabular}{ccc}
\hline \multicolumn{3}{c}{ Data Provided by Tay et al. [40] } \\
\hline Flow Rate $(\mathrm{ml} / \mathrm{min})$ & Heat Input $(\mathrm{W})$ & $h\left(\mathrm{~W} / \mathrm{m}^{2} . \mathrm{K}\right)$ \\
7563.25 & 20 & 3185 \\
14376.994 & 20 & 3207 \\
\multicolumn{3}{c}{ Data from the current Research } \\
Flow Rate $(\mathrm{ml} / \mathrm{min})$ & Heat Input $(\mathrm{W})$ & $h\left(\mathrm{~W} / \mathrm{m}^{2} . \mathrm{K}\right)$ \\
3583.356 & 20 & 2078 \\
\hline
\end{tabular}

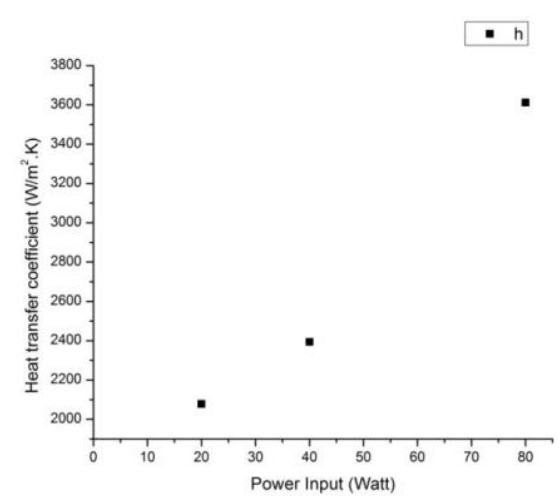

Figure 8. Heat transfer coefficient vs. power input

Figure 8 depicts effect of power input on heat transfer coefficient. It clearly indicates that with increase in power input $h$ value increases. There is a significant increase when power input changes from 40 to 80 Watt. But due to set-up constraint beyond that it is not recommended. Data at 20Watt power input is compared with the data available from Tay et al. [40] and shown in Table 5. It can be observed that comparable heat transfer coefficient has been achieved in the present investigation even by the application of around $50 \%$ less coolant.

\subsection{Experimental uncertainty}

Table 6. Measured uncertainties in the experiments

\begin{tabular}{cc}
\hline Relevant Parameters & Error \\
\hline Test specimen (length, breadth and & $\mathrm{B}= \pm 0.05 \%, \pm 0.05 \%, \pm$ \\
width) & $0.1 \%$ \\
Nozzle Height & $\mathrm{B}= \pm 1 \%$ \\
Water flow rate & $\mathrm{B}= \pm 1.4 \%$ \\
Air flow rate & $\mathrm{B}= \pm 2 \%$ \\
Thermocouple wire & $\mathrm{B}= \pm 2.4^{\circ} \mathrm{C}$ \\
Thermocouple location & $\mathrm{B}= \pm 1 \%$ \\
Temperature measurement & $\mathrm{B}= \pm 2.1^{\circ} \mathrm{C}$ \\
Heat flux & $\mathrm{S}= \pm 3 \%$ \\
Heat Transfer Coefficient & $\mathrm{S}= \pm 3 \%$ \\
\hline
\end{tabular}

In the present investigation, the uncertainty analysis was performed on the experimental results for the measured parameters. In the analysis, the measured parameters are found to be the major sources of errors during the tests. Tests are repeated for at least 5 times for the error analysis. The effort was made to minimize these errors for better accuracy in the investigation. According to uncertainty methodology by ASME test code PTC 19.8-1983, the errors are expressed in terms of two components: (1) Systematic or Bias error $(B)$, due to faults in the measuring instruments involved in the investigations, and (2) Random or Precession error $(S)$, due to the imperfection in explaining the parameters being measured, due to noise in the system [41]. The systematic errors should be very low for achieving the higher accuracy in the experimental values. Hence, primarily, the measuring instruments are calibrated so as to achieve the low systematic errors. Specific measuring instruments are employed for the parameters such as mass flow rate of water, air and temperature during microchannel cooling experiments. For each of the test parameters the maximum controlled error values are determined and depicted in Table 6 . The bias errors for the flow rates are determined as per the rotameter precision data available. The (working range for) centrifugal pump (includes): fluid $(0-95)^{0} \mathrm{C}$, atmospheric temperature up to $56^{\circ} \mathrm{C}$ and optimum pressure of 10 bars from a range of $0-45^{\circ} \mathrm{C}$ while, 6 bars from $45-95{ }^{0} \mathrm{C}$. K-type thermocouples are aligned $100^{\circ} \mathrm{C}$. A standard thermocouple wire was utilized in each experimentation for minimizing fluctuation in temperature. In order to achieve accurate temperature during the experimentation, thermocouples are to be embedded in the specified holes of the workpiece. Hence, careful observation has to be implied for accurate insert of the thermocouple, workpiece and specified location by incorporating thermal paste to minimize the air gap. Both the temperature measuring instruments were calibrated at ice and boiling points. 
Thermocouple measured an error in the range from 0.2 to $0.1^{0} \mathrm{C}$ in case of ice point while, $0.16-0.6{ }^{0} \mathrm{C}$ for boiling point.

A set of five repetitive experiments were conducted for calculating the mean cooling rate and heat transfer coefficient. After a rigorous experimentation, mean value and uncertainty has been observed $\pm 1.40 \%$ which depicts the accuracy of test trial.

\section{CONCLUSIONS}

Response surface method (RSM) was employed to optimize the complex spray mechanisms on microchannels. Results from actual experimental set-up were generated and the influencing parameters were optimized for achieving higher heat transfer coefficient from the microchannel surface of dimension $0.025 \mathrm{~mm} \times 0.027 \mathrm{~mm}$, having 11 numbers of rectangular grooves of hydraulic diameter $150 \mu \mathrm{m}$. Thickness of the plate was $4 \mathrm{~mm}$. The other variables in the present problem were nozzle-to-plate distance, air and water pressures. The experiments were carried out based on the response surface design of experiments. The heat transfer coefficient was calculated using Newton's law of cooling assuming negligible heat loss. The optimization of the controlling parameters of the spray was carried out by RSM. Regression equation was generated for heat transfer coefficient during spray and following important conclusions are made.

Test was carried out at the predicted optimal parametric conditions, i.e. for $\mathrm{p}_{\mathrm{w}}=3$ bar and $\mathrm{p}_{\mathrm{a}}=1$ bar, Nozzle height $=$ $17.425 \mathrm{~mm}$. The same procedure was followed to calculate heat transfer coefficient in those conditions.

In the repeat experiment at the optimal conditions, $h$ value was found to be $2394.31 \mathrm{~W} / \mathrm{m}^{2}-\mathrm{K}$. Comparing this data of $h$ with the primary data, it confirmed the experimental validity with a minor deviation. This may be due to the experimental set up limitations, instead of taking the optimal values the data taken are nearly equal to that, i.e. $\mathrm{p}_{\mathrm{w}}=3 \mathrm{bar}, \mathrm{p}_{\mathrm{a}}=1$ bar, Nozzle height $=18 \mathrm{~mm}$.

Effect of power input on heat transfer coefficient was also studied. It was observed that there is a significant increase in heat transfer coefficient when power input increased from 40 to 80 Watt. But due to set-up constraint beyond that it was not recommended. Data at $20 \mathrm{Watt}$ power input was compared with the data available from Tay et al. [40]. Comparable heat transfer coefficient has been achieved by the application of around $50 \%$ less coolant.

\section{REFERENCES}

[1] Chakraborty M, Anand R, Rao PS, Sen S, DasGupta S. (2017). Oscillating nanofluid droplet for micro-cooling. Sensors Actuators B Chem 239: 562-570. https://doi.org/10.1016/j.snb.2016.06.145

[2] Modak M, Chougule SS., Sahu SK. (2017). An experimental investigation on heat transfer characteristics of hot surface by using $\mathrm{CuO}-$ Water nanofluids in circular jet impingement cooling. Journal of Heat Transfer 140(1): 012401. https://doi.org/10.1115/1.4037396

[3] Visaria M, Mudawar I. (2008a). Theoretical and experimental study of the effects of spray inclination on two-phase spray cooling and critical heat flux.
International Journal of Heat and Mass Transfer 51(9): 2398-2410.

https://doi.org/10.1016/j.ijheatmasstransfer.2007.08.010

[4] Visaria M, Mudawar I. (2008b). Effects of high subcooling on two-phase spray cooling and critical heat flux. International Journal of Heat and Mass Transfer 51(21): 5269-5278. https://doi.org/10.1016/j.ijheatmasstransfer.2008.02.045

[5] Tilton CL, Tilton DE. (2005). Etched open microchannel spray cooling. U.S. Patent 6(952): 346.

[6] Kandlikar SG, Bapat AV. (2007). Evaluation of jet impingement, spray and microchannel chip cooling options for high heat flux removal. Heat Transfer Engineering 28(11): 911-923. https://doi.org/10.1080/01457630701421703

[7] Toda S. (1972). A study of mist cooling ( $1^{\text {st }}$ ReportInvestigation of mist cooling). Heat Transfer-Japanese Research 1: 39-50.

[8] Holman JP, Kendall CM. (1993). Extended studies of spray cooling with Freon-113. International Journal of Heat and Mass Transfer 36(8): 2239-2241. https://doi.org/10.1016/S0017-9310(05)80155-3

[9] Hall DD, Mudawar I. (1995). Experimental and numerical study of quenching complex-shaped metallic alloys with multiple, overlapping sprays. International Journal of Heat and Mass Transfer 38(7): 1201-1216. https://doi.org/10.1016/0017-9310(94)00244-P

[10] Rybicki JR, Mudawar I. (2006). Single-phase and twophase cooling characteristics of upward-facing and downward-facing sprays. International Journal of Heat and Mass Transfer 29(1-2): 5-16. https://doi.org/10.1016/j.ijheatmasstransfer.2005.07.040

[11] Liang G, Mudawar I. (2017). Review of spray cooling Part 1: Single-phase and nucleate boiling regimes, and critical heat flux. International Journal of Heat and Mass Transfer 115: 1174-1205. https://doi.org/10.1016/j.ijheatmasstransfer.2017.06.029

[12] Wang Y, Liu M, Liu D, Xu K, Chen Y. (2010). Experimental study on the effects of spray inclination on water spray cooling performance in non-boiling regime. Experimental Thermal and Fluid Science 34(7): 933-942. https://doi.org/10.1016/j.expthermflusci.2010.02.010

[13] Oliphant K, Webb BW, McQuay MQ. (1998). An experimental comparison of liquid jet array and spray impingement cooling in the non-boiling regime. Experimental Thermal and Fluid Science 18(1): 1-10. https://doi.org/10.1016/S0894-1777(98)10013-4

[14] Yan M, Lane M, Kannewurf CR, Chang RPH. (2001). Highly conductive epitaxial $\mathrm{CdO}$ thin films prepared by pulsed laser deposition. Appl. Phys. Lett 78(16): 2342. https://doi.org/10.1063/1.1365410

[15] Shedd TA. (2007). Next generation spray cooling: high heat flux management in compact spaces. Heat Transfer

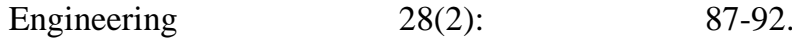
https://doi.org/10.1080/01457630601023245

[16] Hsieh SS, Hsu YF, Wang ML. (2014). A microspraybased cooling system for high powered LEDs. Energy Conversion and Management 78: 338-346. https://doi.org/10.1016/j.enconman.2013.10.066

[17] Deng W, Gomez A. (2011). Electrospray cooling for microelectronics. International Journal of Heat and Mass Transfer 54(11): 2270-2275. https://doi.org/10.1016/j.ijheatmasstransfer.2011.02.038

[18] Coursey JS, Kim J, Kiger KT. (2005). Spray cooling of 
small-pitched, straight-finned, copper heat sinks. International Mechanical Engineering Congress and Exposition 271-277. https://doi.org/10.1115/IMECE2005-81210

[19] Fabbri M, Dhir VK. (2005). Optimized heat transfer for high power electronic cooling using arrays of microjets. Journal of Heat Transfer 127(7): 760-769. https://doi.org/10.1115/1.1924624

[20] Labergue A, Gradeck M, Lemoine F. (2015). Comparative study of the cooling of a hot temperature surface using sprays and liquid jets. International Journal of Heat and Mass Transfer 81: 889-900. https://doi.org/10.1016/j.ijheatmasstransfer.2014.11.018

[21] Chow LC, Sehmbey MS, Pais MR. (1997). High heat flux spray cooling. Annual Review of Heat Transfer 8(8): 291. https://doi.org/10.1615/AnnualRevHeatTransfer.v8.80

[22] Cerruto E, Manetto G, Longo D, Failla S, Schillaci G. (2017). A laboratory system for nozzle spray analysis. Chemical Engineering Transactions 8: 751-756. https://doi.org/10.3303/CET1758126

[23] Wu J, Yan W, Liu M, Tian L, Zhang R. (2017). Numerical simulation of spray cooling gas with high temperature and velocity in compressor inter-stage. Chemical Engineering Transactions 61: 979-984. https://doi.org/10.3303/CET1761161

[24] Mohapatra SS, Ravikumar SV, Pal SK, Chakraborty S. (2013). Ultra fast cooling of a hot steel plate by using high mass flux air atomized spray. Steel Research International 84(3): pp. 229-236. https://doi.org/10.1002/srin.201200157

[25] Ravikumar SV, Jha JM, Tiara AM, Pal SK, Chakraborty S. (2014). Experimental investigation of air-atomized spray with aqueous polymer additive for high heat flux applications. International Journal of Heat and Mass Transfer 72: 362-377. https://doi.org/10.1016/j.ijheatmasstransfer.2014.01.024

[26] Hou Y, Tao Y, Huai X, Zou Y, Sun D. (2018). Numerical simulation of multi-nozzle spray cooling heat transfer. International Journal of Thermal Sciences 125: 81. https://doi.org/10.1016/j.ijthermalsci.2017.11.011

[27] Jung EY, Park CU, Lee DH, Kim KM, Cho HH. (2018). Effect of the injection angle on local heat transfer in a showerhead cooling with array impingement jets. International Journal of Thermal Sciences 124: 344 https://doi.org/10.1016/j.ijthermalsci.2017.10.033

[28] Abdalrahman KH, Specht E. (2014). Influence of salt mixture on the heat transfer during spray cooling of hot metals. International Journal of Heat and Mass Transfer 78:

76-83. https://doi.org/10.1016/j.ijheatmasstransfer.2014.06.070

[29] Aamir M, Qiang L, Xun Z, Wang H, Ullah R. (2016). Study on ultra-fast cooling behaviors of water spray cooled stainless steel plates. Experimental Heat Transfer 29(3): 299-321. https://doi.org/10.1080/08916152.2014.976722

[30] Hsieh SS, Luo SY. (2016). Droplet impact dynamics and transient heat transfer of a micro spray system for power electronics devices. International Journal of Heat and Mass Transfer 92: 190-205. https://doi.org/10.1016/j.ijheatmasstransfer.2015.08.099

[31] Yang J, Chow LC, Pais MR. (1996). Nucleate boiling heat transfer in spray cooling. Journal of Heat Transfer 118(3): 668-671. https://doi.org/10.1115/1.2822684

[32] Horacek B, Kim J, Kiger KT. (2004). Spray cooling using multiple nozzles: visualization and wall heat transfer measurements. IEEE Transactions on Device and Materials Reliability 4(4): 614-625. https://doi.org/10.1109/TDMR.2004.838399

[33] Horacek B, Kiger KT, Kim J. (2005). Single nozzle spray cooling heat transfer mechanisms. International Journal of Heat and Mass Transfer 48(8): 1425-1438. https://doi.org/10.1016/j.ijheatmasstransfer.2004.10.026

[34] Liao J, Dimopoulos Eggenschwiler P, Furrer R, Wang M, Boulouchos K. (2018). Heat transfer characteristics of urea-water spray impingement on hot surfaces. International Journal of Heat and Mass Transfer 117: 447. https://doi.org/10.1016/j.ijheatmasstransfer.2017.10.031.

[35] Chen RH, Chow LC, Navedo JE. (2004). Optimal spray characteristics in water spray cooling. International Journal of Heat and Mass Transfer 47(23): 5095-5099. https://doi.org/10.1016/j.ijheatmasstransfer.2004.05.033

[36] Mudawar I, Estes KA. (1996). Optimizing and predicting CHF in spray cooling of a square surface. Journal of Heat Transfer 118:

672-679. https://doi.org/10.1115/1.2822685

[37] Lam PAK, Prakash KA. (2017). Effect of magnetic field on natural convection and entropy generation in $\mathrm{Al}_{2} \mathrm{O}_{3}$ /water nanofluid-filled enclosure with twin protruding heat sources. Journal of Thermal Science and $\begin{array}{lll}\text { Engineering Applications } & 924502 .\end{array}$ https://doi.org/10.1115/1.4035810

[38] Prinn KB, Costantino HR, Tracy M. (2002). Statistical modeling of protein sprays drying at the lab scale. AapsPharmscitech 3(1): 32-39. https://doi.org/10.1208/pt030104.

[39] Nayak SK, Mishra PC, Parashar SKS. (2016). Enhancement of heat transfer by water_ $\mathrm{Al}_{2} \mathrm{O}_{3}$ and water_ $\mathrm{TiO}_{2}$ nanofluids jet impingement in cooling hot steel surface. Journal of Experimental Nanoscience 11(16):

$1253-1273$ https://doi.org/10.1080/17458080.2016.1209789

[40] Tay AA, Ang SS, Lwin LO. (2006). An experimental study of slot-jet impingement and mist cooling of microprocessors. Thermal and Thermomechanical Proceedings 10th Intersociety Conference on Phenomena in Electronics Systems. ITHERM, San Diego, CA, USA, pp.

$175-180$ https://doi.org/10.1109/ITHERM.2006.1645340

[41] Abernethy RB, Benedict RP, Dowdell RB. (1985). ASME measurement uncertainty, ASME J. Fluids Eng. 107: 161164. https://doi.org/10.1115/1.3242450

\section{NOMENCLATURE}

$\begin{array}{ll}\mathrm{HTC}(h) & \text { heat transfer coefficient, } \mathrm{W} / \mathrm{m}^{2}-\mathrm{K} \\ \mathrm{H} & \text { nozzle to surface distance, } \mathrm{mm} \\ \mathrm{p} & \text { pressure, bar } \\ \mathrm{T} & \text { temperature, }{ }^{\circ} \mathrm{C} \\ q & \text { heat flux, } \mathrm{W} / \mathrm{m}^{2}\end{array}$

\section{Subscripts}

$\mathrm{S}$

c

w water

a air 